\title{
Knowledge of Prenatal Exercise among Expectant Women from Selected Health Facilities, Kakamega County, Kenya
}

\author{
Edinah Sabiri*, Oloo Micky Olutende, Issah K. Wabuyabo, Vurigwa Esther \\ Department of Health Promotion and Sports Science, Masinde Muliro University of Science and Technology \\ *Corresponding author: micky.oloo.mf@gmail.com
}

\begin{abstract}
The relationship between exercise or physical activity and women reproductive health is a controversial issue especially characterized by lack of understanding on the type of physical activity or exercise and the exact effect on expectant women. This is evidenced by lack of medical guidelines on exercise in pregnancy up to 1985.The traditional medical view ruled out exercise for expectant mothers. The society in general prevented girls from participating in exercise for fear that it might compromise their potential as future mothers. However recent research show that exercise during pregnancy has benefits to the mother and foetus. Modern medicine appreciates that both expectant mothers need exercise for good health. The study assessed the knowledge and attitude of expectant mothers on benefits of exercise during pregnancy. A descriptive survey research design sought information from 306 expectant mothers of 15 -39 years attending antenatal clinics in selected medical facilities of Kakamega County in Kenya. Self-administered questionnaires were used to collect data from the subjects on maternal characteristics and knowledge on benefits of exercise during pregnancy. Descriptive statistics were used to analyze the level of knowledge and perceived benefits of exercise during pregnancy. The results showed majority of the subjects were between $20-24$ years (33.3\%). $17 \%$ of the sampled population did not know that exercise was useful in pregnancy despite $71.6 \%$ having been active in sports while in school. The subjects showed knowledge of exercise in, preventing incontinence (80.4\%), decreased risk of pre-eclampsia (71.6\%) and decreasing the risk of gestational diabetes and hypertension at $65.7 \%$ and $68.6 \%$ respectively. The results indicated that there was strong association between the level of education and, knowledge $\left(X^{2}(3, N=306)=39.109, p=0.02\right)$ in the role of exercise during pregnancy. Therefore it is important to note that the level of education is important for quality pregnancy.
\end{abstract}

Keywords: knowledge, expectant women, prenatal, exercise

Cite This Article: Edinah Sabiri, Oloo Micky Olutende, Issah K. Wabuyabo, and Vurigwa Esther, "Knowledge and Attitude towards Prenatal Exercise among Expectant Women from Selected Health Facilities, Kakamega County, Kenya.” Journal of Physical Activity Research, vol. 3, no. 1 (2018): 55-59. doi: 10.12691/jpar-3-1-9.

\section{Introduction}

Physical Activity (PA) is widely accepted as being beneficial to the health of a person and its regular participation has become an important component of a healthy lifestyle [1,2] Exercise as a type of physical activity is a planned structured and repetitive bodily movement requiring physical or mental effort done to improve health [3]. While exercise is beneficial to the health of individuals across the ages [4], it is even more critical for expectant women because partially a sedentary lifestyle places them at increases risks of pregnancy related health complications and compromised baby health.

For many decades the relationship between exercise and women reproductive health has been a controversial issue with skepticism over safety and the benefits in pregnancy. The controversy is characterized by lack of understanding on the type of exercise and the exact effect on expectant women, knowledge and perception on the benefits by pregnant women, level of education, race/ethnicity [5,6]. However modern medicine appreciates that expectant mothers need exercise for good health. Emerging evidence show that relevant exercises can be initiated and continued in pregnancy as it is safe and of significant benefits to a mother and foetus $[7,8]$.

Scientific literature suggests that low to moderate impact exercise regime for pregnant mothers Performed for about 30 minutes on most days of the week and gradually progressed over a period of time can be followed to improve overall fitness [7]. These exercises include aerobics exercises such as aerobics, swimming, cycling, walking, dancing; core stability, pelvic floor exercises, breathing exercises, postural education and back care [7].. Foot \& leg exercises, and pelvic tilting can be performed in sitting or half-lying positions, whereas transversus and pelvic floor exercises can be carried out in any position [9].

Performing all or combination of different exercises under the supervision of a Physical therapist results in various benefits [4,10]. Antenatal exercises focus on 
maintaining physical fitness and cardiovascular endurance in those who undertake to perform them [10]. Exercise during pregnancy has proved over time to lead to relief of pain strengthened muscles in preparation for labour and support for loosened joints, enhanced circulation, increased flexibility, increased capacity (endurance), increased energy level, combats fatigue, decreases muscle tension, promotes relaxation and a positive self-image. Prenatal exercise prevents Gestational diabetes. A review of 8 studies by Tobias et al [11] showed that regular exercise before pregnancy reduced the risk of gestational diabetes by $55 \%$ while engagement in early pregnancy decreased the risk by $24 \%$.

There have been studies in various developed and developing countries to assess awareness of the benefits of exercise during pregnancy. However, literature on awareness of expectant mothers regarding benefits of exercise during pregnancy in Kenya is scarce. Makinde, Adeyemo \& Ogundele, [3] recommends that there should be increased awareness on the usefulness of prenatal exercise to pregnant women to increase engagement in exercise. Hence this current study aims at exploring the knowledge among pregnant women from Kenya on usefulness of exercise in pregnancy.

\section{Methodology}

The study employed descriptive survey study design. This design enabled the study to obtaining data that described status on pregnant women's exercise perceptions as it was. Approval certificate was collected from the ethical committee of Masinde Muliro University to allow the researcher to carry out the study. The study was conducted in Kakamega County, Kenya. All public and private medical facilities offering antenatal care were selected through identification from the county ministry of Health. Convenience sampling was employed to recruit 306 pregnant women regularly attending prenatal clinic, aged between 15 and 40 years in all trimester of pregnancy. This technique was chosen for the study to increase the range of potential participants and the women attended clinics at different times of the week. A two-page self-administered questionnaire was completed by participating women and consisted of section A with closed ended questions to capture demographic information and some questions related to the study and Section $\mathrm{B}$ with adopted and modified five Likert scale items to capture knowledge of the subjects on the study. The responses were on a five-point rating of Strong Agree (SA) -5, Agree (A)-4, Undecided (U)-3, Disagree (D)-2 and Strongly Disagree (SD)-1. The questionnaire was reviewed by experts in the department of Sports Science MMUST and its contents validated after pilot study. Informed consent of respondents was sought prior to filling the questionnaire. Statistical Packages for Social Sciences (SPSS) computer packages version 23 was used to code, organize and analyze the data. Descriptive statistics of mean, percentages standard deviation, frequency distribution were used to summarize data. Chi square was used to determine association between perception of exercise and the respondent characteristics.

\section{Results}

Three hundred and six (306) subjects participated in the study.168 (54.9\%) of the total respondents were within the range of 15-24 years, 114 (37.2\%) were within the age range of (25-34) years and 24 (7.8\%) of the respondents were above the age of 34 years old. The results revealed further that a majority 132 (43.1\%) had primary level education, 117 (38.2\%) attended secondary school and 57 (18.6\%) had tertiary education. Demographic characteristics of respondents are presented in Table 1. $87(28.4 \%)$ of women reported that they were not active in sports while $219(71.6 \%)$ were active in sports out of which $254(82.4 \%)$ of women agreed that exercise was useful in pregnancy and 54(17.6\%) disagreed. On prior deliveries, the results revealed that 279(91.2\%) had normal delivery while 27(8.8\%) delivered through caesarian section. Table 3 shows knowledge in usefulness of exercise in pregnancy

Table 1. Demographic characteristics of respondents $(\mathrm{N}=306)$

\begin{tabular}{cccc}
\hline Characteristic & & Frequency & Percentage (\%) \\
\hline Age in years & $\mathbf{1 5 - 1 9}$ & 66 & 21.6 \\
& $\mathbf{2 0 - 2 4}$ & 102 & 33.3 \\
& $\mathbf{2 5 - 2 9}$ & 72 & 23.5 \\
& $\mathbf{3 0 - 3 4}$ & 42 & 13.7 \\
& $\mathbf{3 5 - 3 9}$ & 24 & 7.8 \\
Level of education & Primary & 132 & 43.1 \\
& Secondary & 117 & 38.2 \\
& College & 42 & 13.7 \\
& University & 15 & 4.9 \\
\hline
\end{tabular}

Table 2. Association between knowledge and level of education

\begin{tabular}{lcccc}
\hline & $\begin{array}{c}\text { Poor } \\
\text { Knowledge } \\
(\mathbf{6 0 \%}>)\end{array}$ & $\begin{array}{c}\text { Good } \\
\text { Knowledge } \\
(\mathbf{6 0 \%}<)\end{array}$ & $\begin{array}{c}\text { O.R } \\
(\mathbf{9 5 \%} \text { C.I) }\end{array}$ & $\begin{array}{c}\boldsymbol{\chi}^{2} \\
\text { (p value) }\end{array}$ \\
\hline \multicolumn{2}{l}{ Level of education } & & & $\mathbf{0 . 0 2}$ \\
Primary & $(30 \%)$ & $(70 \%)$ & $2.171(1.359-3.825)$ & \\
Secondary & $(35 \%)$ & $(65 \%)$ & $1.098(0.636-2.920)$ & \\
College & $(25 \%)$ & $(55 \%)$ & $0.110(0.022-0.544)$ & \\
University & $(10 \%)$ & $(90 \%)$ & $*$ & \\
\hline
\end{tabular}

Table 3. Summary of extra questions asked

\begin{tabular}{lcc}
\hline Characteristic & \multicolumn{2}{c}{ Frequency } \\
\hline & Yes & No \\
Participation in sports in school & $219(71.6 \%)$ & $87(28.4 \%)$ \\
Had C/S delivery before & $27(8.8 \%)$ & $279(91.2 \%)$ \\
Is exercise useful in pregnancy & $254(82.4 \%)$ & $54(17.6 \%)$ \\
Total & $\mathbf{1 0 0}$ & $\mathbf{1 0 0}$ \\
\hline
\end{tabular}

Respondents were asked questions in order to check their knowledge of the benefits of prenatal exercises. Table 4 shows knowledge in usefulness of prenatal exercise in pregnancy. Majority of the respondents agreed that exercise in pregnancy reduced the risks of incontinence $(86.4 \%)$, reduced chances of caesarian section during delivery (80.6\%), led to better sleep (73.5), improved self-image (73.5\%) and enhanced muscular skeletal function (72.5\%). However, few respondents were aware of the role of prenatal exercises in controlling weight gain during pregnancy $(62.8 \%)$, decreasing the risk of gestational diabetes $(65.7 \%)$ and reducing time for 
labour (66.7\%). Results from chi square test showed that there was a statistically significant relationship between level of education and knowledge $X^{2}(3, N=306)=39.109$, $p=0.02$. Logistic regression was done and respondents who were single were 2.2 times more likely ( $\mathrm{OR}=2.171$, 95\% C.I, 1.359-3.825) to belong to the 'poor knowledge 'group that the 'good knowledge 'group compared to the university graduates.

Table 4. Knowledge of respondents on benefits of exercises in pregnancy $(N=306)$.

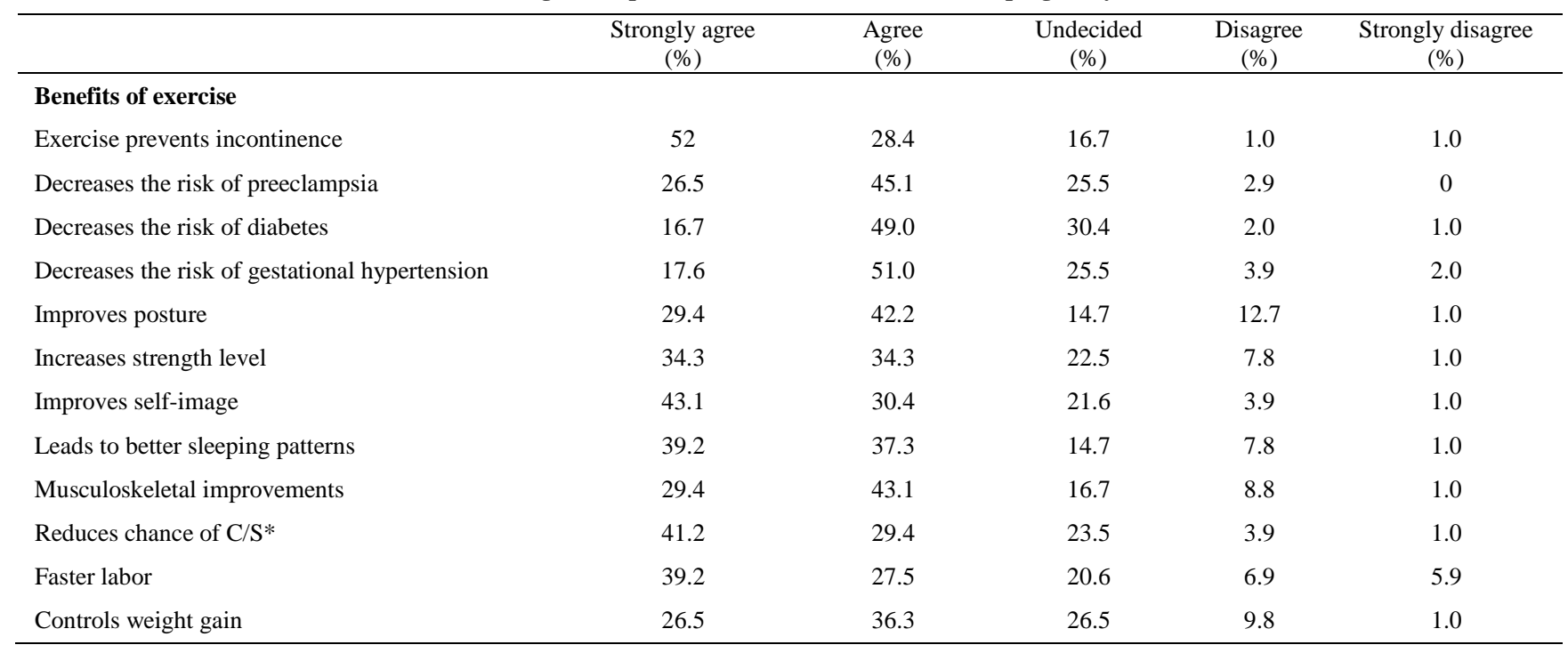

* C/S- Caesarean section.

\section{Discussion}

This study was conducted on pregnant females attending antenatal clinics to assess the knowledge regarding the usefulness of prenatal exercise. The total number of participants for our study was 306, $44.6 \%$ of them were within the age range of 15-24 years, $37.2 \%$ were within the age range of $25-34$ years and $7.8 \%$ fall into group of 35 years and above. Educational level of the respondents showed that $43.1 \%$ attended primary education, $38.2 \%$ went to secondary school and 18.6 had tertiary education. Most of the sampled subjects were active in sports $71.6 \%$ while in school out of which $91.2 \%$ had normal prior delivery a previous study found that most of the women engaged in physical exercise based on self-prescription [12]. It has been found from previous studies that subjects' characteristics such as age [13] and level of education $[14,15]$ and experience in infant and maternal issues [16] significantly influence knowledge and attitude of mothers towards exercise in pregnancy. This finding is consistent with some previous reports that have associated higher participation in physical activity or exercise with higher education levels $[14,17,18,19,20]$. Petersen et al. [21] in a study on correlates of physical activity among pregnant women in the United States found that pregnant women meeting the moderate or vigorous physical activity recommendations were more likely to be younger, nonHispanic white, more educated, not married, nonsmokers, and to have higher incomes. [22] in a review on exercise in pregnancy found higher education and income as predictors of higher exercise participation during pregnancy. Furthermore, only $17.6 \%$ of women in the study perceived exercise as not useful in pregnancy while a majority of the samples seemed to agree that exercise was useful. This could have been influenced by sports participation in school which boosted positive attitude towards exercise. Ribeiro and Milanez [15] demonstrated that 67\% of respondents had adequate knowledge. These contrasting results between our study and the previous studies show the positive influence of education and society on the awareness of pregnant mothers It is believed then that the findings of this study on attitude towards exercise may have been influenced by the maternal and sociodemographic characteristics of the subjects. Nonetheless, the result of a similar study done by Mbada et al [12] revealed that the knowledge about benefits of antenatal exercises was not influenced by maternal sociodemographic characteristics.

With regards to usefulness of prenatal exercise during pregnancy, Majority of the respondents agreed that exercise in pregnancy, reduced chances of caesarian section delivery, led to better sleep, improved self-image and enhanced muscular skeletal function. This finding is in tandem with recent studies that have reported positive knowledge of exercise [23]

Studies done have shown a paradigm shift in attitudes toward exercise during pregnancy over the past two decades with increasing numbers of pregnant women participating in physical activities, exercises, and sports activities [7,24]

Similar study carried out among pregnant women in attending antenatal outpatient department by Sarfraz et al. [4] showed $95.2 \%$ of the women agreed that physiotherapy has a positive role in pregnancy. In addition, the study revealed that most women believed that prenatal exercise prevents incontinence (80.4\%). However, few respondents were aware of the role of prenatal exercises in controlling weight gain during pregnancy decreasing the risk of gestational diabetes and reduced labour time, this was a contrary finding from studies carried out in other countries [23]. This again shows the importance of education and social influence and also the lack of exposure to modernization and changes in the society. Similarly, a study done in Brazil by Ribeiro and Milanez [15] demonstrated good knowledge on exercise during 
pregnancy and correlated to better schooling among the respondents.

\section{Recommendation}

The outcome of this study underscores the need for interaction of physiotherapist with other health care professionals in order to ensure that the antenatal exercises performed by pregnant women. The study also indicated that positive role played by health education programmes in motivating pregnant women to engage actively in physical exercises. Further these implemented measures should be analyzed for their impact on pregnancy in both pre-and postnatal outcome.

In spite of the fact that, knowledge and practice of exercise during pregnancy among the study population was less when compared to previous studies, the reason for this outcome is easily identified as lack of awareness in the issue. Hence, health care programs should be organized to improve the awareness of antenatal mothers on exercise during pregnancy. Studies should be conducted to analyze whether the measures taken are having a positive impact on the women and increasing their motivation to practice exercising. Studies can also be done to evaluate the positive impact of exercise on pregnancy and on perinatal outcome. This will help to encourage even the group which is less motivated. The practice of simple and regular exercise in pregnancy will significantly improve physical wellbeing in pregnancy and good perinatal outcome. The cost is insignificant, but the benefits in terms of gestational wellbeing and health are considerable. These benefits can easily be gained through simple interventions at community level, providing social support and providing a healthy lifestyle. Identifying myths and misconceptions in the society would objectively encourage a change in attitude. This study discusses the rationale behind the different knowledge and attitude of respondents and suggests educational tools to initiate behavioral changes. We also propose better counseling and exercise prescriptions for the patients.

\section{Limitations}

The outcome of this study is limited in its generalizability and needs to be validated in other settings. This study does not take into account available knowledge of contraindications to exercise during pregnancy.

\section{Conclusion}

Our results suggest that the pregnant Kenyan woman's attitude towards the role of exercise during pregnancy is favorable; however, the knowledge of the different antenatal exercises and their benefits is inadequate.

\section{References}

[1] Tero, P., Samppa, T., Ari, H., \& Urho, M. K. (2017). Exercise therapy for functional capacity in chronic diseases: an overview of meta-analyses of randomized controlled trials. British Journal of Sports Medicine, bjsports-2016-097132.

[2] Lee, I. M., Shiroma, E. J., Lobelo, F., Puska, P., Blair, S. N., \& Katzmarzyk, P. T. (2012). Effect of physical inactivity on the world's major non-communicable diseases. The Lancet, 380(9838), 219-229.

[3] Makinde O, Adeyemo F \& Ogundele B. Perception of pregnant mothers attending antenatal clinic on usefulness of prenatal exercise in Osogbo, Osun state, Nigeria. Health Science Journal. 2014; 8 (2).

[4] Sarfraz M, Islami D, Hameed U, Hasan Danish S, Ahmad F. Role of Physical Therapy in antenatal care as perceived by the clients-a cross sectional survey on pregnant females attending antenatal OPD. Pakistan Journal of Medicine and Dentistry 2013; 1(01): 34-46.

[5] Ebeigbe PN, Igberase GO. Antenatal care: a comparison of demographic and obstetric characteristics of early and late attenders in the Niger Delta, Nigeria. Medical Science Monitor. 2005; 11(11): 529-532.

[6] Thornton P L, Kieffer EC, Salabarr'ia-Pena Y. Weight, diet, and physical activity-related beliefs and practices among pregnant and postpartum latino women: the role of social support. Maternal and Child Health Journal. 2006; 10(1): 95-104.

[7] American Congress of Obstetricians and Gynaecologists (ACOG) and Committee on Obstetric Practice, “'Exercise during pregnancy and the postpartum period'. ACOG Committee Opinion Number 267,” Obstetrics \& Gynecology, vol. 99, no. 1, pp. 171-173, 2002.

[8] C. P. Ribeiro and H. Milanez, "Knowledge, attitude and practice of women in Campinas, S ao Paulo, Brazil with respect to physical exercise in pregnancy: a descriptive study," Reproductive Health, vol. 8, no. 1, p. 31, 2011.

[9] Keefer EJ. From Pain to Performance, 2005. Available from: http://www.nyu.edu/classes/keefer/pain/pain1.htm[Accesed November 7, 2013).

[10] Nayak R, Paes L, Gupta C, Kumar VK, Narayan A, Thunga S, Mithra PP. Knowledge, Perception, and Attitude of Pregnant Women Towards the Role of Physical Therapy in Antenatal Care A Cross Sectional Study. Online J Health Allied Scs. 2015; 14(4): 6. Available at URL: http://www.ojhas.org/issue56/2015-4-6.html.

[11] Tobias, D. K., C. Zhang, et al. (2011). "Physical activity before and during pregnancy and risk of gestational diabetes mellitus: a meta-analysis.” Diabetes Care 34(1): 223-229.

[12] Mbada, C.E., Adebayo, O.E., Awotidebe, T.O. (2015). Practice and pattern of antenatal and postnatal exercise among Nigerian Women. A cross sectional study. International journal of women's health and reproductive sciences, 3(2), 93-98.

[13] Zhang and D. A. Savitz, "Exercise during pregnancy among US women," Annals of Epidemiology, vol. 6, no. 1, pp. 53-59, 1996.

[14] Evenson KR, Savitz DA, Huston SL. Lesure-time physical activity among pregnant women in the US. Paediatr Perinat Epidemiol 2004; 18(6): 400-7.

[15] Ribeiro CP, Milanez H. Knowledge, attitude and practice of women in Campinas, São Paulo, Brazil with respect to physical exercise in pregnancy: A descriptive study. Reprod Health 2011; 8: 31.

[16] H. M. Whitford, B. Alder, and M. Jones, “A cross-sectional study of knowledge and practice of pelvic floor exercises during pregnancy and associated symptoms of stress urinary incontinence in North-East Scotland,” Midwifery, vol. 23, no. 2, pp. 204-217, 2007.

[17] Mottola MF, Campbell MK. Activity patterns during pregnancy. Can J Appl Physiol 2003; 28(4): 642-53.

[18] Domingues MR, Barros AJ. Leisure-time physical activity during pregnancy in the 2004 Pelotas Birth Cohort Study. Rev Saude Publica 2007; 41(2): 173-80.

[19] Larson-Meyer DE. Effect of postpartum exercise on mothers and their offspring: a review of the literature. Obes Res 2002; 10(8): 841-53.

[20] Davies GA, Wolfe LA, Mottola MF, MacKinnon C, Society of Obstetricians and gynecologists of Canada, SOGC Clinical Practice Obstetrics Committee. Joint SOGC/CSEP clinical practice guideline: exercise in pregnancy and the postpartum period. Can J Appl Physiol 2003; 28(3): 330-41.

[21] Petersen AM, Leet TL, Brownson RC. Correlates of physical activity among pregnant women in the United States. Med Sci Sports Exerc 2005; 37(10): 1748-53. 
[22] Gaston A, Cramp A. Exercise during pregnancy. A review of patterns and determinants. J Sci Med Sport 2011; 14(4): 299-305.

[23] M. Abedzadeh, M. Taebi, Z. Sadat, and F. Saberi, "Knowledge and performance of pregnant women referring to Shabihkhani hospital on exercises during pregnancy and postpartum periods,"
Journal of JahromUniversity of Medical Sciences, vol. 8, no.4, 2011.

[24] R. Barakat, M. Pelaez, R. Montejo, M. Luaces, and M. Zakynthinaki, "Exercise during pregnancy improves maternal health perception: a randomized controlled trial," American Journal of Obstetrics and Gynecology, vol. 204, no. 5, pp. 402.e1-402. e7, 2011. 